\title{
Clinical prospective evaluation of zirconia-based three-unit posterior fixed dental prostheses: Up-to ten-year results
}

\author{
Ioannidis, Alexis ; Bindl, Andreas
}

\begin{abstract}
OBJECTIVES Only a few studies exist, which assess the clinical long-term behavior of all-ceramic FDPs in the posterior region. The aim of the present prospective clinical study was to evaluate the clinical performance of posterior three-unit FDPs manufactured from Y-TZP after a service period up to 10 years. METHODS 55 patients received 59 three-unit FDPs in the posterior region of the maxilla or mandible. Abutment teeth were prepared and full-arch impressions were taken. Definitive casts were fabricated and optically scanned. Frameworks were fabricated with computer-aided design (CAD) and manufacturing (CAM) technology. Y-TZP frameworks were veneered and adhesively luted to the abutment teeth. Baseline and follow-up examinations (service time: $\geq 48$ months) were recorded by applying modified United States Public Health Services (USPHS) rating criteria. Cumulative survival rate was analyzed with Kaplan-Meier. Percentage of biological and technical complication was calculated. RESULTS Fifty-three patients with 57 FDPs attended the last follow-up visit and a mean observation period of the remaining was $6.3 \pm 1.9$ years was calculated. Biological complications occurred in $17.5 \%$, technical complications in $28 \%$ of the FDPs. The 10 -year cumulative survival rate amounted $85.0 \%$. Three FDPs failed to survive, two due to a root fracture of the abutment tooth and one due to secondary caries. CONCLUSIONS Three-unit FDPs made from Y-TZP, veneered with ceramic offer a treatment option with a high rate of chipping. However, the manufacturing processes nowadays are modified in order to avoid this complication. CLINICAL SIGNIFICANCE The results of the present investigation suggest that three-unit Y-TZP posterior FDPs may are a possible treatment option. However, a high rate of chipping can be expected.
\end{abstract}

DOI: https://doi.org/10.1016/j.jdent.2016.01.014

Posted at the Zurich Open Repository and Archive, University of Zurich

ZORA URL: https://doi.org/10.5167/uzh-126603

Journal Article

Accepted Version

Originally published at:

Ioannidis, Alexis; Bindl, Andreas (2016). Clinical prospective evaluation of zirconia-based three-unit posterior fixed dental prostheses: Up-to ten-year results. Journal of Dentistry, 47:80-85.

DOI: https://doi.org/10.1016/j.jdent.2016.01.014 


\section{Clinical prospective evaluation of zirconia-based three-unit posterior fixed dental prostheses: up-to ten-year results.}

Short title: 10-year clincial evaluation of zirconia-based 3-unit posterior FDPs.

Alexis loannidis ${ }^{1}$ and Andreas Bindl ${ }^{2, *}$

* Corresponding author

1: Post-graduate student. Clinic of Preventive Dentistry, Periodontology and Cariology, Center of Dental Medicine, University of Zurich, Plattenstrasse 11, 8032 Zurich, Switzerland (alexis.ioannidis@zzm.uzh.ch) ${ }^{1}$

2: Senior lecturer. Clinic of Preventive Dentistry, Periodontology and Cariology, Center of Dental Medicine, University of Zurich, Plattenstrasse 11, 8032 Zurich, Switzerland. (andreas.bindl@zzm.uzh.ch / Tel: +41 4426133 30, Fax: +41 4426133 29)

Keywords: all-ceramic restorations, fixed dental prostheses, zirconia, clinical trials, CAD/CAM

${ }^{1}$ present address: Clinic of Fixed and Removable Prosthodontics and Material Sciences, Center of Dental Medicine, University of Zurich, Plattenstrasse 11, 8032 Zurich, Switzerland 


\title{
Clinical prospective evaluation of zirconia-based three-unit posterior fixed dental prostheses: up-to 10-year results.
}

\begin{abstract}
Objectives: Only a few studies exist, which assess the clinical long-term behavior of all-ceramic FDPs in the posterior region. The aim of the present prospective clinical study was to evaluate the clinical performance of posterior three-unit FDPs manufactured from Y-TZP after a service period up to 10 years.
\end{abstract}

Methods: 55 patients received 59 three-unit FDPs in the posterior region of the maxilla or mandible. Abutment teeth were prepared and full-arch impressions were taken. Definitive casts were fabricated and optically scanned. Frameworks were fabricated with computer-aided design (CAD) and manufacturing (CAM) technology. Y-TZP frameworks were veneered and adhesively luted to the abutment teeth. Baseline and follow-up examinations (service time: $\geq 48$ months) were recorded by applying modified United States Public Health Services (USPHS) rating criteria. Cumulative survival rate was analyzed with Kaplan-Meier. Percentage of biological and technical complication was calculated.

Results: Fifty-three patients with 57 FDPs attended the last follow-up visit and a mean observation period of the remaining was $6.3 \pm 1.9$ years was calculated. Biological complications occurred in $17.5 \%$, technical complications in $28 \%$ of the FDPs. The 10 -year cumulative survival rate amounted $85.0 \%$. Three FDPs failed to survive, two due to a root fracture of the abutment tooth and one due to secondary caries.

Conclusions: Three-unit FDPs made from Y-TZP, veneered with ceramic offer a treatment option with a high rate of chipping. However, the manufacturing processes nowadays are modified in order to avoid this complication.

Clinical significance: The results of the present investigation suggest that three-unit Y-TZP posterior FDPs may are a possible treatment option. However, a high rate of chipping can be expected. 


\section{INTRODUCTION}

When it comes to replace a missing posterior tooth, tooth-supported fixed partial dentures (FDPs) are a well-documented treatment option with high survival rates. ${ }^{1}$ Veneered gold- or metalalloys are still the 'gold standard' for the fabrication of posterior FDPs. ${ }^{1}$ They offer good mechanical properties, while from an esthetic point of view it may be challenging to veneer the dark framework, especially in areas with limited space. All-ceramic materials offer an alternative in terms of better optical properties with a more tooth-resembling color and a higher translucency. Furthermore, the patient's demand for metal-free restorations is increasing and all-ceramic restorations come along with a good biocompatibility. ${ }^{2}$ Also due to the risen costs for the production of metal-frameworks, the need of developing all-ceramic materials that withstand high occlusal forces were needed.

Nowadays, a variety of different ceramic materials are available for all-ceramic crowns, FDPs and their frameworks. Besides the conventional glass-ceramics, high- strength ceramics like alumina and zirconia have been introduced. While glass-ceramics offer good optical but low physical properties, alumina and zirconia ceramics exhibit a superior stability but lower translucency. Due to the weak optical properties of alumina and zirconia, they usually were used as a framework material and have to be veneered with tooth-colored ceramics. ${ }^{3}$ Existing since the early 1990s, zirconia appears as the most suitable all-ceramic material for FDPs. ${ }^{1}$

Pure zirconium-dioxide $\left(\mathrm{ZrO}_{2}\right)$ can exist in three temperature-dependent phases: monoclinic (room temperature to $\left.1^{\prime} 170^{\circ} \mathrm{C}\right)$, tetragonal $\left(1^{\prime} 170^{\circ} \mathrm{C}\right.$ to $\left.2^{\prime} 370^{\circ} \mathrm{C}\right)$ and cubic $\left(2^{\prime} 370^{\circ} \mathrm{C}\right.$ up to the melting point). $\mathrm{ZrO}_{2}$, in its pure condition is at room temperature unsuitable for structural or mechanical applications. ${ }^{4} \mathrm{By}$ adding $\mathrm{Y}_{2} \mathrm{O}_{3}$ to $\mathrm{ZrO}_{2}$, it is possible to stabilize the dense tetragonal phase to a socalled yttria-stabilized zirconia (Y-TZP). This process leads to an inhibited further propagation in cases of crack-formation within the material and therefore gives Y-TZP a great potential for stressbearing. ${ }^{4}$ By this reason, Y-TZP exhibits fracture strength of 900 to 1 '400 MPa and a fracture toughness of 5 to $10 \mathrm{MPa} \mathrm{m}{ }^{1 / 2}$, which is superior to all currently available sintered ceramics. ${ }^{3,5,6}$

The productions of such frameworks, made by high-strength ceramic zirconia, have become feasible with the introduction of computer-aided design/computer-aided manufacturing (CAD/CAM) systems in dentistry. ${ }^{7-9}$ By using CAD/CAM procedures, the time for fabrication, the material costs and the associated costs for production of FDP-frameworks can be reduced in comparison to 
conventionally manufactured metal-frameworks. In general, in the CAD/CAM-workflow three steps can be defined: 1) Scanning of the preparation intraorally or from a cast model; 2) Digital design of the reconstruction (CAD) and 3) Machining the digitally designed reconstruction out of a pre-fabricated blank (CAM) ${ }^{10,11}$ Usually, the Y-TZP blanks get milled in a pre-sintered condition. In order to obtain the final density and strength of the milled framework, sintering at high temperature is necessary. Machining the work piece enlarged by this amount compensates the sinter-shrinkage of about 25 to $30 \% .^{7,12}$

So far, numerous clinical studies have confirmed zirconia as sufficient strong to function as framework material for FDPs. ${ }^{13-15}$ However, current data indicate the chipping of the veneering ceramic is often observed as a technical complication. ${ }^{1,16,17}$ Since now, only a few studies exist, which assess the clinical long-term behavior of all-ceramic FDPs in the posterior region. ${ }^{17-20}$ Thus, the want for additional long-term investigations on all-ceramic FDPs is essential.

Therefore, the aim of the present prospective study was to evaluate the clinical performance of posterior three-unit FDPs manufactured from Y-TZP after a service period up to 10 years. It was hypothesized that the long-term survival rate of such FDPs would not differ from those reported in the literature for conventional metal-ceramic FDPs.

\section{MATERIALS AND METHODS}

\section{Study population}

Following approval by the ethical committee (Ref. Nr. StV 02/09) of the University of Zurich 55 patients with the indication of at least one three-unit FDP in the posterior were recruited for this study. The abutment teeth had to be either a premolar and a molar or two molars. The FDP had to replace just one missing premolar or one missing molar. Patients had to be periodontally healthy and show no signs of actual parafunctional habits or untreated tempo-mandibular disorders. All patients were informed in detail about differences between metal-ceramic and full-ceramic restorations and their advantages and disadvantages. A signed informed consent was obtained from all the patients prior to any treatments. 


\section{Clinical Procedure}

All previous restorations and build-up materials, as well as base materials and caries, were completely removed to prepare a sound basis for the new restoration. If required, vital teeth were built up using a functional adhesive (Syntac Classic \& Heliobond; Ivoclar Vivadent, Schaan, Liechtenstein) and a light-curing resin-based fine-hybrid composite (Tetric; Ivoclar Vivadent, Schaan, Liechtenstein). If endodontic treated teeth showed not enough surfaces for retention, an endodontic ceramic post was set (Cera Post; Brasseler, Lemgo, Germany / Panavia 21 TC; Kuraray, Tokyo, Japan). The abutment teeth were prepared according to the requirements for all ceramic FPDs with circular butt joint margins of approximately 0.8 to $1.0 \mathrm{~mm}$ width, a tapering angle of 10 to 12 degrees, an occlusal reduction of at least $1.5 \mathrm{~mm}$ and a minimal abutment height of $3-4 \mathrm{~mm}$.

After preparation, full-arch impressions were taken using a silicone material (Honigum; DMG Dental, Hamburg, Germany). Direct temporary FDPs were fabricated (Luxatemp; DMG, Hamburg, Germany). Prior to cementation of the temporary FDP (Temp Bond NE; Kerr Hawe, Bioggio, Switzerland), dentine was sealed a self-etching primer and adhesive as well as a bonding agent (Syntac Classic \& Heliobond; Ivoclar Vivadent, Schaan, Liechtenstein).

\section{Fabrication of the Y-TZP FDPs}

First, definitive casts were fabricated out of hard stone plaster (Fuji Rock; GC International, Leuven, Belgium). All frameworks were manufactured by a CAD/CAM system (in Lab; Sirona, Bensheim, Germany). An optical scan was taken from the FDP preparation, using a pinpoint laser scanner (in Lab; Sirona, Bensheim, Germany). The CAD construction of the framework was made by means of a software (in Lab; Version 3.1, Sirona, Bensheim, Germany). According to the manufacturer's guidelines, the minimal connector dimension of the framework was $9 \mathrm{~mm}^{2}$. The minimal framework thickness accounted $0.5 \mathrm{~mm}$ at the vertical crown walls and $0.7 \mathrm{~mm}$ occlusally. With a milling unit (in Lab; Sirona, Bensheim, Germany), the framework was milled out of presintered zirconia blank (Vita In-Ceram 2000YZ-Cubes; Vita Zahnfabrik, Bad Säckingen, Germany). The enlarged milled framework was sintered to full density at a temperature of $1^{\prime} 560^{\circ} \mathrm{C}$ (ZYrcomat; Vita Zahnfabrik, Bad Säckingen, Germany) for 2 hours according to manufactures instruction, resulting in shrinkage to the wanted framework dimension. After checking for fit in the patient mouths, the 
framework was manually veneered with a veneering ceramic (Vitadur Alpha; Vita Zahnfabrik, Bad Säckingen, Germany).

\section{Moisture Control and Adhesive Placement}

The temporary FDP was removed and the preparations were carefully cleaned using a finishing diamond (grain size: $25 \mu \mathrm{m}$, Nr. 2504; Intensiv, Viganello-Lugano, Switzerland). Cotton rolls (Pharmadoc; Zürich, Switzerland) and dry angle (Dry Tip; Mölnycke, Sweden) were used to manage salivation and gingival fluid during adhesive placement. Adhesive pretreatment of the dentin was applied using a self-etching primer, adhesive and a bonding agent (Syntac Classic \& Heliobond; Ivoclar Vivadent, Schaan, Liechtenstein).

After air-abrasion with aluminum oxide (grain size: $50 \mu \mathrm{m}$, pressure: 2.5 bar) and cleaning with alcohol of the internal parts, the reconstruction was adhesively placed (Panavia 21 TC; Kuraray, Tokyo, Japan). Excess luting material was partially removed and the margins of the restoration were covered with a protective layer (Panavia F Oxyguard II; Kuraray, Tokyo, Japan) for 8 minutes. After polymerization, the removal of excess luting material was completed with a scaler (M23 Universal Scaler; Deppeler, Rolle, Switzerland).

\section{Clinical Examination}

Baseline examination was recorded by applying modified United States Public Health Services (USPHS) rating criteria. ${ }^{21,22}$ Patients whose FDPs had been in service for at least 48 months and no such follow-up data were available, were invited for follow-up examination. Patients who did not appear to the follow-up examination where excluded from the study.

Two clinicians assessed the FDPs. The examiners had previously trained on other clinical cases until ratings were equal. In addition, Plaque- ${ }^{23}$ and Papillary-Bleeding-Indices ${ }^{24}$ were recorded for six sites (mesiobuccal, buccal, distobuccal, distoligual, lingual, mesiolingual) on abutment teeth and on Ramfjord control teeth ${ }^{25}$. Ramfjord control teeth included non-restored and restored teeth.

\section{Statistical Analysis}

Data were coded and analyzed in SPSS Statistics 20.0 (SPSS Inc., Chicago, IL, USA). Descriptive statistic such as mean and standard deviation (SD) and the 95\% confidence interval (95\% 
$\mathrm{Cl}$ ) was applied to the data. The statistical unit in calculating the survival rate was the FDP. FDP survival was defined the FDP was in situ at the time of the last follow-up visit. The cumulative survival rate was analyzed with the Kaplan-Meier nonparametric method. The percentage of biological and technical complication was calculated.

For the USPHS-criteria, the number of single ratings, A, B, C, (D), (E) were expressed as a percentage of the total number of ratings per criterion.

For comparing the Plaque- and Papillary-Bleeding-Indices, the measured values were pooled and averaged for the abutment and the Ramfjord control teeth. A Wilcoxon test was applied to compare the test and control teeth. After Bonferroni correction for multiple testing, the significance level was set at $p<2.5 \%(\alpha / k=0.05 / 2)$.

\section{RESULTS}

\section{Patient demographics and distribution of the FDPs}

Fifty-five patients (32 women, 23 men) received 59 FDPs between 2002 and 2006. At time of insertion, the mean age of the patients accounted $52.6 \pm 10.1$ years. The distribution of the replaced teeth is shown in Table 1. In total, 25 premolars and 34 molars were replaced. Twenty-nine FDPs were placed in the upper jaw and 30 FDPs in the lower jaw.

\section{Clinical outcome of FDPs}

The last recall was carried out in April 2012. Fifty-three patients with 57 FDPs attended the last follow-up visit. Two patients were considered as drop out. One patient could not come because of medical reasons; the other patient had changed the dentist and did not want to come for a follow-up visit.

The mean observation period of the remaining 57 FDPs was $6.3 \pm 1.9$ years (95\% Cl: $5.8 ; 6.9$ years; median: 5.6 years). The shortest observation period was 2.6 years due to a biological complication. Beside from that, the observation period varied from 4.0 years to 10.2 years.

Comparing the Plaque- and Papillary-Bleeding-Indices of the test (abutment teeth) and the control teeth (Ramfjord control teeth), no statistically significant difference for the Plaque-Index ( $p=$ 0.0138 ) but for the Papillary-Bleeding Index ( $p=0.8001$; test $>$ control) could be revealed. 


\section{Survival and complication rates}

The results of the ratings according to the USPHS criteria are depicted in Table 2. Derived from that, biological and technical complications can be described. Biological complications occurred in 10 out of 57 FDPs, which leads to a biological complication rate of $17.5 \%$. The observed complications were: loss of tooth vitality $(3 / 57=5.2 \%)$, root fracture of the abutment tooth $(2 / 57=$ $3.5 \%)$, periodontal complications $(2 / 57=3.5 \%)$, secondary caries $(2 / 57=3.5 \%)$ and need for endodontic revision due to apical periodontitis $(1 / 57=1.8 \%)$. The occurrences of biological complications are, in chronological order, listed in Table 3. As technical complication, 16 chippings occurred during the observation period, resulting in a technical complication rate of $28.0 \%$. According to the USPHS-criteria, the chippings were either rated as "small, localized chipping" $(6 / 57=10.5 \%)$ or as "extended chipping" $(10 / 57=17.5 \%)$. Depending on the clinical situation, the chippings could be repaired with composite or could be polished. No severe technical complication, i.e. framework fracture, occurred. The chronological occurrence of the technical complications is listed in Table 4.

In total, 54 FDPs (94.7\%) did survive and 3 FDPs (5.3\%) failed to survive. The failures were all caused by biological and not by technical failures. Namely, one root fracture of the abutment tooth occurred after a service time of 2.6 years. A second FDP had to be removed (7.9 years in service) also due to a root fracture. A third FDP did not survive because of secondary caries of an abutment tooth (8.1 years in service). According to Kaplan-Meier, the 10-year cumulative survival rate for this cohort was $85.0 \%$ (Figure 1).

\section{Discussion}

The present study aimed to evaluate the clinical long-term outcome of posterior three-unit FDPs with a Y-TZP framework. The 10-year cumulative survival rate was $85.0 \%$ after a mean observation period of 6.3 years. Three FDPs had to be removed due to biological complications.

The results are in concordance with a present clinical investigation, evaluating the long-term clinical outcome of three-unit posterior glass-infiltrated zirconia reinforced alumina ceramic FDPs. ${ }^{17}$ After 10 years of function, they showed a survival rate of $84.6 \%$ in a worst-case scenario, which rated all dropouts as failures. However, the regular 10-year cumulative survival rate was with $93.6 \%$ higher than reported in our study. ${ }^{17}$ Another study, which investigated 26 three- to five- unit zirconia-based 
FDPs, found a 10 -year survival rate of $67 \% .{ }^{18}$ Based on the outcomes of a systematic review, a 5year survival rate of densely-sintered zirconia FDPs of $90.4 \%$ can be expected. ${ }^{26}$ In this review 16 prospective and retrospective studies met the inclusion criteria and were used for the meta-analysis. ${ }^{26}$ In the present study, the most severe complications, which led to the loss of the FDPs, were biological. $3.5 \%$ of the FDPs investigated in our study had to be removed because of root fracture of the abutment tooth. In comparison, known from the mentioned systematic review, the estimated rate of densely sintered zirconia FDPs lost due to abutment tooth fracture in 5 years amounts $1.0 \%$ (95\% Cl: $0.6 \% ; 1.9 \%) .{ }^{26} 1.8 \%$ of the here investigated FDPs, namely one, was removed due to secondary caries. The meta-analysis in the systematic review revealed that within 5-years the estimated risk for this complication is $1.9 \%(95 \% \mathrm{Cl}: 1.3 \% ; 7.5 \%)$ and thus comparable to our findings. ${ }^{26}$ We assume that the biological complications described in this investigation, which led to the failures of the FDPs, cannot be directly connected to the tested material.

Commonly, the most frequent biological complication is loss of tooth vitality: $2.2 \%$ estimated after 5 years. $(95 \% \mathrm{Cl}: 0.5 \% ; 8.6 \%)$. In an other study, loss of vitality of the abutment teeth was seen in $8 \%$ after 10 years and over an observation period of 25 years, $17 \%$ of the initially vital teeth lost their vitality. ${ }^{27}$ In our cohort, loss of tooth vitality was with $7.0 \%$ also the most frequent biological adverse event. Probably this could be due to the evident amount of tooth loss during conventional crown preparation. 68 to $76 \%$ of the tooth-substance get lost, when a posterior crown is prepared. ${ }^{28}$

The most frequent technical complication reported in the present investigation was chipping of the veneering ceramic $(29.8 \%)$. Compared to the study of Chaar et al. ${ }^{17}$, which observed a chipping rate of $37.7 \%$, our findings revealed less such adverse events. However, the mean observation time in the mentioned study (9.7 years) was longer compared to our investigation. ${ }^{17}$ Our results are more comparable to the study of Sax et al. ${ }^{18}$, which found minor and major chippings of the veneering ceramic in $32 \%$ of the cases at 10 years. A significant correlation of the span of the FDPs and the incidence of chipping was seen with a 4.9 times higher probability for the occurrence of chipping in 4and 5-unit FDPs than in three FDPs. ${ }^{18}$ Beside marginal discolorations (28.5 \% cumulative 5-year complication rate) ceramic chipping (19.5\%) and ceramic fractures $(14.5 \%)$ of the veneering ceramic can be expected as the main technical complication. ${ }^{26}$ Despite the high incidence of veneering material fractures, the survival rate of zirconia based FDPs mainly is not affected. ${ }^{29}$ The majority of the chippings does not impair function or aesthetics of the FDPs and can be polished or repaired, as 
we did in our investigation. ${ }^{29}$ However, today zirconia FDPs were manufactured differently compared to the present material and methods. First of all, the software to design the zirconia frameworks, offer the opportunity for anatomically designed frameworks. This has shown to be more favorable to prevent from ceramic chipping. Secondly, nowadays, a slow-cooling procedure is used during the veneering process to avoid internal stress within the veneering ceramic. This knowledge was not present at the time of producing the FDPs for this investigation.

By manually layering the veneering ceramic on the framework, micro-pores and the inclusion of air cannot be avoided. Therefore, the homogeneity and hence, the stability and the veneering ceramic may is affected. ${ }^{30}$ As mentioned above, chipping of the veneering ceramic is a very oftenobserved technical complication - generally and in our investigation. To overcome the high rate of ceramic chipping of manually layered FDPs, alternative veneering techniques, alternative veneering materials or even monolithic FDPs without veneering ceramic are available. Kern et al. reported on a chipping rate of $3.0 \%$ after 5 years and $6.1 \%$ after 10 years with monolithic lithium-disilicate FDPs. ${ }^{19}$ However, the Grohmann et al. compared posterior zirconia FDPs veneered either manually or by means of a CAD/CAM manufactured lithium disilicate veneering ceramic. ${ }^{31}$ The rate of chipping was comparable in both groups after 1 year of function and occurred in small amounts. ${ }^{31}$ With the alternative technique of overpressing a zirconia framework with lithium-disilicate ceramic, however, a double as high rate of chipping ( $40 \%)$ after 3 -years was observed, when compared to conventionally veneered FDPs $(20 \%)$ in another investigation. ${ }^{32}$ To the best of our knowledge, well-designed clinical studies on monolithic zirconia FDPs are lacking. Since the mechanical properties of zirconia are superior to other ceramic materials, chipping is not expected in such kind of monolithic FDPs. With the marketing of high translucent zirconia and the opportunity to characterize the reconstructions, this material may appears promising when used for monolithic zirconia FDPs. However, this has to be proven in future studies.

A drawback of the present study is that there is no control group with metal-ceramic FDPs. Randomized controlled trials, comparing zirconia-based FDPs and metal-ceramic FDPs are sparse. A randomized controlled clinical trial of Sailer et al. ${ }^{33}$ found similar a survival rate of zirconia-based FDPs in comparison to metal-ceramic FDPs after 3 years in function. In a actual systematic review, the clinical success of tooth-supported zirconia-based FDPs was analyzed. ${ }^{29}$ It was concluded, that the 5-year survival rate of tooth-supported zirconia-based FDPs is acceptable and comparable to 
metal-ceramic FDPs. ${ }^{29}$ However, more well designed studies long-term studies ideally with a control group are needed.

\section{CONCLUSIONS}

Within the limitations of this clinical study, it can be concluded that three-unit FDPs made from Y-TZP, veneered with ceramic offer a treatment option with a high rate of chipping. However, the manufacturing processes nowadays are modified in order to avoid this complication. 


\section{References}

1. Sailer I, Pjetursson BE, Zwahlen M, Hammerle CH. A systematic review of the survival and complication rates of all-ceramic and metal-ceramic reconstructions after an observation period of at least 3 years. Part II: Fixed dental prostheses. Clinical Oral Implants Research 2007; 18 Suppl 3: 86-96.

2. Mallineni SK, Nuvvula S, Matinlinna JP, Yiu CK, King NM. Biocompatibility of various dental materials in contemporary dentistry: a narrative insight. Journal of Investigative and Clinical Dentistry 2013; 4(1): 9-19.

3. Miyazaki T, Nakamura T, Matsumura H, Ban S, Kobayashi T. Current status of zirconia restoration. Journal of Prosthodontic Research 2013; 57(4): 236-61.

4. Bahat Z, Mahmood DJ, Vult von Steyern P. Fracture strength of three-unit fixed partial denture cores (Y-TZP) with different connector dimension and design. Swedish Dental Journal 2009; 33(3): 149-59.

5. Christel P, Meunier A, Heller M, Torre JP, Peille CN. Mechanical properties and short-term in-vivo evaluation of yttrium-oxide-partially-stabilized zirconia. Journal of Biomedical Materials Research 1989; 23(1): 45-61.

6. Guazzato M, Albakry M, Ringer SP, Swain MV. Strength, fracture toughness and microstructure of a selection of all-ceramic materials. Part II. Zirconia-based dental ceramics. Dental Materials 2004; 20(5): 449-56. 
7. Tinschert J, Natt G, Hassenpflug S, Spiekermann H. Status of current CAD/CAM technology in dental medicine. International Journal of Computerized Dentistry 2004; 7(1): $25-45$.

8. Chevalier J. What future for zirconia as a biomaterial? Biomaterials 2006; 27(4): 53543.

9. Denry I, Kelly JR. State of the art of zirconia for dental applications. Dental Materials 2008; 24(3): 299-307.

10. Beuer F, Schweiger J, Edelhoff D. Digital dentistry: an overview of recent developments for CAD/CAM generated restorations. British Dental Journal 2008; 204(9): $505-11$.

11. Fasbinder DJ. Computerized technology for restorative dentistry. American Journal of Dentistry 2013; 26(3): 115-20.

12. Bindl A, Mormann WH. Fit of all-ceramic posterior fixed partial denture frameworks in vitro. International Journal of Periodontics and Restorative Dentistry 2007; 27(6): 567-75.

13. Jung RE, Sailer I, Hammerle CH, Attin T, Schmidlin P. In vitro color changes of soft tissues caused by restorative materials. International Journal of Periodontics and Restorative Dentistry 2007; 27(3): 251-7. 
14. Eschbach S, Wolfart S, Bohlsen F, Kern M. Clinical evaluation of all-ceramic posterior three-unit FDPs made of In-Ceram Zirconia. The International Journal of Prosthodontics 2009; 22(5): 490-2.

15. Schmitt J, Holst S, Wichmann M, Reich S, Gollner M, Hamel J. Zirconia posterior fixed partial dentures: a prospective clinical 3-year follow-up. The International Journal of Prosthodontics 2009; 22(6): 597-603.

16. Al-Amleh B, Lyons K, Swain M. Clinical trials in zirconia: a systematic review. Journal of Oral Rehabilitation 2010; 37(8): 641-52.

17. Chaar MS, Passia N, Kern M. Ten-year clinical outcome of three-unit posterior FDPs made from a glass-infiltrated zirconia reinforced alumina ceramic (In-Ceram Zirconia). Journal of Dentistry 2015; 43(5): 512-7.

18. Sax C, Hammerle CH, Sailer I. 10-year clinical outcomes of fixed dental prostheses with zirconia frameworks. International Journal of Computerized Dentistry 2011; 14(3): 183202.

19. Kern M, Sasse M, Wolfart S. Ten-year outcome of three-unit fixed dental prostheses made from monolithic lithium disilicate ceramic. Journal of the American Dental Association 2012; 143(3): 234-40.

20. Chaar MS, Kern M. Five-year clinical outcome of posterior zirconia ceramic inlayretained FDPs with a modified design. Journal of Dentistry 2015. 
21. Ryge G, Snyder M. Evaluating the clinical quality of restorations. Journal of the American Dental Association 1973; 87(2): 369-77.

22. Bindl A, Mormann WH. Survival rate of mono-ceramic and ceramic-core CAD/CAM-generated anterior crowns over 2-5 years. European Journal of Oral Sciences 2004; 112(2): 197-204.

23. Silness J, Loe H. Periodontal Disease in Pregnancy. Ii. Correlation between Oral Hygiene and Periodontal Condtion. Acta Odontologica Scandinavica 1964; 22: 121-35.

24. Saxer UP, Muhlemann HR. [Motivation and education]. SSO: Schweizerische Monatsschrift fur Zahnheilkunde 1975; 85(9): 905-19.

25. Ramfjord S. Indices for prevalence and incidence of periodontal disease. Journal of Periodontology 1959; (57): 746-52.

26. Pjetursson BE, Sailer I, Makarov NA, Zwahlen M, Thoma DS. All-ceramic or metalceramic tooth-supported fixed dental prostheses (FDPs)? A systematic review of the survival and complication rates. Part II: Multiple-unit FDPs. Dental Materials 2015; 31(6): 624-39.

27. Valderhaug J, Jokstad A, Ambjornsen E, Norheim PW. Assessment of the periapical and clinical status of crowned teeth over 25 years. Journal of Dentistry 1997; 25(2): 97-105. 
28. Edelhoff D, Sorensen JA. Tooth structure removal associated with various preparation designs for posterior teeth. International Journal of Periodontics and Restorative Dentistry 2002; 22(3): 241-9.

29. Le M, Papia E, Larsson C. The clinical success of tooth- and implant-supported zirconia-based fixed dental prostheses. A systematic review. Journal of Oral Rehabilitation 2015.

30. Beuer F, Schweiger J, Eichberger M, Kappert HF, Gernet W, Edelhoff D. Highstrength $\mathrm{CAD} / \mathrm{CAM}$-fabricated veneering material sintered to zirconia copings--a new fabrication mode for all-ceramic restorations. Dental Materials 2009; 25(1): 121-8.

31. Grohmann P, Bindl A, Hammerle C, Mehl A, Sailer I. Three-unit posterior zirconiaceramic fixed dental prostheses (FDPs) veneered with layered and milled (CAD-on) veneering ceramics: 1-year follow-up of a randomized controlled clinical trial. Quintessence International 2015; 46(10): 871-80.

32. Naenni N, Bindl A, Sax C, Hammerle C, Sailer I. A randomized controlled clinical trial of 3-unit posterior zirconia-ceramic fixed dental prostheses (FDP) with layered or pressed veneering ceramics: 3-year results. Journal of Dentistry 2015; 43(11): 1365-70.

33. Sailer I, Gottnerb J, Kanelb S, Hammerle CHF. Randomized controlled clinical trial of zirconia-ceramic and metal-ceramic posterior fixed dental prostheses: a 3-year follow-up. The International Journal of Prosthodontics 2009; 22(6): 553-60. 


\section{TABLES}

\begin{tabular}{|c|c|c|c|c|}
\hline Replaced tooth & 16 & 15 & 25 & 26 \\
\hline Number of FDPs & 6 & 4 & 11 & 8 \\
\hline Number of FDPs & 5 & 4 & 6 & 15 \\
\hline Replaced tooth & 46 & 45 & 35 & 36 \\
\hline
\end{tabular}

Table 2 - Clinical criteria according to the USPHS criteria. Rating at the last follow-up visit in percent (\%) and number of patients ( $\mathrm{n}$ ) sorted by the different categories.

\begin{tabular}{|c|c|c|c|c|}
\hline Category & Rating & Description & & $\bar{n}$ \\
\hline \multirow[t]{4}{*}{ Marginal adaption } & A & $\begin{array}{l}\text { Probe, does not catch, smooth margin } \\
\text { interface }\end{array}$ & 29.8 & 17 \\
\hline & B & $\begin{array}{l}\text { Probe catches at single spots, slight } \\
\text { roughness }\end{array}$ & 59.6 & 34 \\
\hline & C & Probe catches at $50 \%$ of margin length & 10.5 & 6 \\
\hline & D & $\begin{array}{l}\text { Probe catches at } 100 \% \text { of margin } \\
\text { length }\end{array}$ & 0 & 0 \\
\hline \multirow[t]{4}{*}{ Integrity of FDP } & A & Completely intact & 71.9 & 41 \\
\hline & B & $\begin{array}{l}\text { Small, localized chipping, } \\
\text { recontourable }\end{array}$ & 10.5 & 6 \\
\hline & C & $\begin{array}{l}\text { Extended chipping, framework } \\
\text { exposed, repair possible }\end{array}$ & 17.5 & 10 \\
\hline & $\mathbf{D}$ & $\begin{array}{l}\text { Fracture of crown/and tooth, loss of } \\
\text { crown }\end{array}$ & 0 & 0 \\
\hline \multirow[t]{3}{*}{$\begin{array}{l}\text { Anatomic form of } \\
\text { FDP }\end{array}$} & A & $\begin{array}{l}\text { Contour completely matching to } \\
\text { neighboring dentition }\end{array}$ & 94.7 & 54 \\
\hline & B & $\begin{array}{l}\text { FDP is slightly under-/ over contoured } \\
\text { (adjustment possible, accepted by } \\
\text { patient) }\end{array}$ & 3.5 & 2 \\
\hline & C & $\begin{array}{l}\text { FDP is significantly under-/over- } \\
\text { contoured; still accepted by patient }\end{array}$ & 1.8 & 1 \\
\hline \multirow[t]{4}{*}{ Secondary caries } & A & $\begin{array}{l}\text { No caries diagnosed clinically at } \\
\text { margin interface }\end{array}$ & 96.5 & 55 \\
\hline & B & Superficial initial cavitation & 0 & 0 \\
\hline & C & $\begin{array}{l}\text { Caries clinically localized, small filling } \\
\text { necessary }\end{array}$ & 1.8 & 1 \\
\hline & $\mathbf{D}$ & $\begin{array}{l}\text { Caries clinically and radiographically } \\
\text { extended, replacement of FDP } \\
\text { necessary }\end{array}$ & 1.8 & 1 \\
\hline \multirow{3}{*}{$\begin{array}{l}\text { Surface texture of } \\
\text { crown }\end{array}$} & A & Smooth, glazed/polished surface & 78.9 & 45 \\
\hline & B & $\begin{array}{l}\text { Slightly rough spots on surface (can } \\
\text { be polished) }\end{array}$ & 21.1 & 12 \\
\hline & C & Roughness on $50 \%$ of the surface & 0 & 0 \\
\hline Color & A & $\begin{array}{l}\text { No discrepancy in color and } \\
\text { translucency in comparison to the }\end{array}$ & 77.2 & 44 \\
\hline
\end{tabular}


neighboring dentition

$\begin{array}{llrr}\text { B } & \begin{array}{l}\text { Minor discrepancy in color and } \\ \text { translucency } \\ \text { Mayor discrepancy in color and } \\ \text { translucency }\end{array} & 22.8 & 13 \\ \text { C } & 0 & 0\end{array}$

Proximal contacts of A FDP

\section{B}

C

Occlusal centric contacts of FDP

A

B

C

Dynamic contacts of $A$ FDP

B

C

Change of sensitivity

X-ray

Patient's satisfaction

\section{A}

B

C

D

A

B

C

D

E

A

B

C
Physiological strength of proximal

contact

Weak but still sufficient proximal

contact

Missing proximal contact

Premature occlusal contact,

recontourable

Missing occlusal contact

Normal protrusion and laterotrusion

contacts

Slightly interfering protrusion

laterotrusion contacts

Significantly interfering protrusion

laterotrusion contacts

No change

Unclear (no discomfort)

Unclear (severe discomfort or pain)

Negative, (with positive sensitivity at baseline)

Unremarkable

Slight excess of luting material

Slight marginal gap visible

Massive marginal gap/massive excess

of luting material visible

Secondary caries, apical lesion, root fracture

Patient satisfied

Short discomfort after treatment

Patient unsatisfied
$73.7 \quad 42$

$21.1 \quad 12$

$5.3 \quad 3$

$93 \quad 53$

$\begin{array}{ll}7 & 4\end{array}$

$70.2 \quad 40$

00

$3.5 \quad 2$

3.52

$98.2 \quad 56$

$1.8 \quad 1$

\section{2}

2

3

53

列

$73.7 \quad 42$

$26.3 \quad 15$

$0 \quad 0$

$93 \quad 53$

$0 \quad 0$

$0 \quad 0$

$1.8 \quad 1$

00
74 
Table 3 - Biological complications in chronological order.

Time-point of biological Description
complication (years of
service)

$2.6+\quad$ root fracture

$4.8 \quad$ loss of tooth vitality

$5.2 \quad$ loss of tooth vitality

$5.7 \quad$ secondary caries

$5.9 \quad$ loss of tooth vitality

6.6 periodontal complication

7.3 periodontal complication

$7.9+\quad$ root fracture

$8.1+\quad$ secondary caries / loss of tooth vitality

10.2 endodontic revision due to apical periodontitis

$\bar{t}=$ led to failure of the FDP

Table 4 - Technical complications in chronological order.

Time-point of technical complication (years of service)

\section{Description}




\section{FIGURES}

Fig. 1. Cumulative 10-year survival rate (85\%) of the yttria-stabilized 3-unit posterior FDPs calculated with the Kaplan Meier nonparametric method.

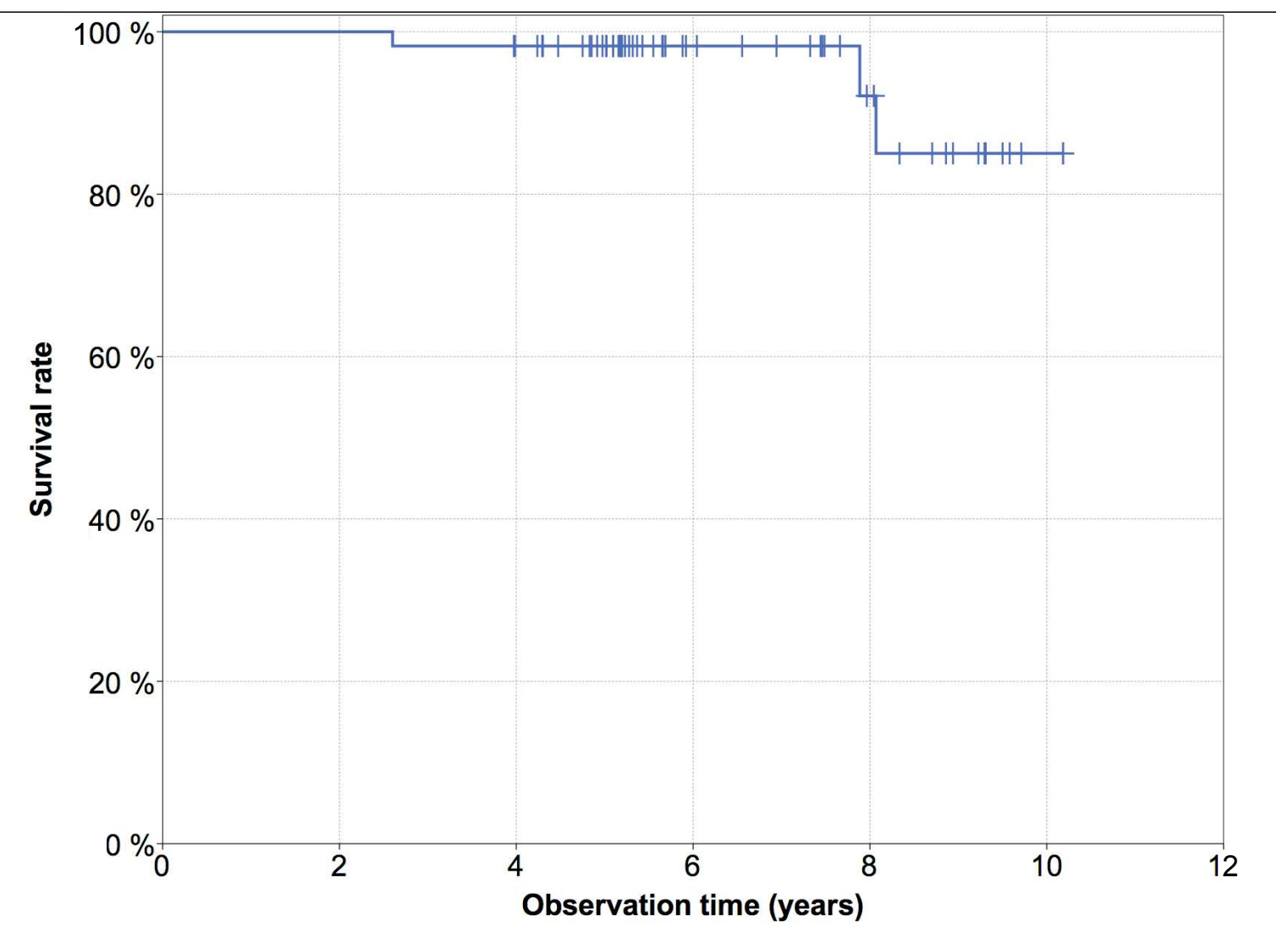


Conflict of interest: This study was supported, in part, by Vita Zahnfabrik, Bad Säckingen, Germany. 